\title{
Segmentation of topographic change by geomorphic units to assess physical habitat transitions in a restored river
}

\author{
Georgios Maniatis \\ School of Environment and Technology, University of Brighton, Brighton, UK. \\ Richard Williams \\ School of Geographical and Earth Sciences, University of Glasgow, Glasgow, UK. \\ Trevor Hoey \\ Department of Civil and Environmental Engineering, Brunel University London, London, UK
}

\begin{abstract}
River restoration schemes that utilise natural processes need to be monitored postimplementation to inform adaptive management, to assess their success at delivering sustained ecological improvements and to contribute to the design of other schemes. All three of these monitoring objectives require an understanding of the geomorphic mechanisms that cause channel adjustment and how they shape the mosaic of geomorphic units that make up physical habitat. In the last decade repeat, high-resolution topographic surveys of river restoration schemes have become commonplace through the application of a range of geomatics technologies including echosounders, laser scanners and Structure from Motion photogrammetry. Such datasets offer opportunities to map geomorphic change and geomorphic unit evolution to quantitatively analyse the relative roles of different processes in generating physical habitat. Here, we present results from an investigation into the morphodynamics of the Whit Beck river restoration scheme, implemented by the West Cumbria Rivers Trust, UK. We use repeat Digital Elevation Models (DEMs) to quantify patterns of erosion and deposition using the Geomorphic Change Detection (GCD) toolbox and to map geomorphic units, using the Geomorphic Unit Tool (GUT). The segmentation of maps of erosion and deposition with maps of geomorphic units quantifies physical habitat transitions. The resulting analysis indicates the different mechanisms of adjustment that generate physical habitat throughout the restoration scheme and how they are linked to different initial conditions
\end{abstract}

\section{INTRODUCTION}

River restoration schemes are commonly evaluated in terms of improved ecological services (Downs and Kondolf, 2002). These enhancements are related to reach-scale morphological changes; local adjustments that increase the variability of sub-reach Geomorphic Units (GUs) generating physical habitat (Beechie et al., 2010; Beletti et al., 2017). Traditionally, the characterization of riverine physical habitats was based on semi-quantitative field assessments and empirical classifications (e.g. Hawkins et al., 1993). This approach has been proven useful for monitoring the development of restoration schemes, but it rarely explains the complex morphodynamics that drive physical habitat transitions. The recent expansion of high-resolution topographic (HRT, Passalacqua et al., 2015) surveys opens the prospect of fully quantitative comparison of the morphological changes after restoration through the detailed mapping of erosion-deposition patterns.

Exploring the full potential of HRT data for evaluating river restoration schemes requires three significant methodological developments. Firstly, analytical tools for differencing Digital Elevation Models (DEMs) from riverscapes while allowing for the coherent modelling of the propagated error in the DEM of Difference (DoD) are required. The Geomorphic Change Detection suite (GCD v.7.10, Wheaton et al., 2010) is a complete and tested (Williams et al., 2017) set of tools that provide the data handling and processing capabilities for extracting robust sediment budget maps from DoDs. It is also necessary to have: a) an unambiguous fluvial taxonomy for the characterisation of GUs (Wheaton et al., 2015) and; b) processing tools for consistently delineating GUs from HRT data. The Geomorphic Unit Toolbox (GUT) is a Python program that uses 
the fluvial taxonomy of Wheaton et al. (2015) (Bangen et al., 2017) and maps objectively the extent of GUs per type of GU. In brief, GUT uses a three-tier framework to map GUs. Tier 1 classifies the valley and flow units using bankfull and low flow extent polygons. Tier 2 classifies topographic shape (concavity, planar, convexity) and form (bowl, trough, planes, wall, saddle, mounds, transition zones). During Tier 3 processing, each Tier 2 unit was classified into Tier 3 geomorphic units using attributes such as, unit position (margin attached, mid-channel or channel spanning), orientation (longitudinal, diagonal, transverse), bankfull water surface slope, ratio of unit width to bankfull width, channel type (main, cut-off, return) and elongation ratio.

Here, we use two successive surveys (from 2014 and 2017) of river Whit Beck (Cumbria, UK) to a) demonstrate the objective mapping of GU (and physical habitat) transitions using the GUT; and, b) show the result of segregating the sediment budget (net volumetric change) over each GU towards linking the morphological changes with the development of specific features. The 2014 survey was acquired using a fusion of Terrestrial Laser Scanning (TLS) of dry areas and an RTKGNSS in-channel survey. The 2017 survey was acquired using a fusion of Structure from Motion photogrammetry and of dry areas and an RTK-GNSS in-channel survey. The in-channel survey featured a point density of c. 1 point $/ \mathrm{m}^{2}$.

\section{METHODS}

The diversion of the Whit Beck (catchment area $11.8 \mathrm{~km}^{2}$, West Cumbria Rivers Trust) restored a $350 \mathrm{~m}$ section of very heavily modified river (works finished in 2014). The scheme has been monitored by an annual series of HRT surveys which include Terrestrial Laser Scanning (TLS), Unmanned Aerial Vehicle (UAV) imagery and Real Time Kinematic (RTK) GNSS point surveying of the riverbed for robust monitoring of in-stream changes. Specifically, the 2014 and 2017 surveys presented here combine Structure-from-Motion Multi-View Stereo (SfM MVS) photogrammetry (using UAV derived images) with point RTK-GNSS bed surveys used to avoid complex bathymetric corrections (Dietrich, 2017). The two DEMs, were generated by interpolating a triangular irregular network (TIN, Lange et al., 2014) which were subsequently converted to 0.2 resolution DEMs using linear interpolation.

Geomorphic change (2014 to 2017) was mapped at an $80 \%$ confidence interval (Vericat et al., 2017) using the GCD software and assuming a spatially constant Standard Deviation Error (SDE) of $0.10 \mathrm{~m}$ (Bangen et al., 2014). To map the GUs, the following inputs were prepared to use with the GUT tool: a low flow extent polygon (digitised from topographic data), a bankfull extent polygon (using the Bankfull Tool in the River Bathymetry Toolkit (McKean et al., 2019) after detrending each DEM of its longitudinal profile), a bankfull centreline, and a thalweg polyline. The average bankfull width for the site (used as a scalar for unit size thresholding) was calculated using the bankfull extent polygon and the bankfull centreline. From the three-tier hierarchical classification implemented in GUT (adapted from Wheaton et al. 2015), here we use Tier 3 which classifies geomorphic and sub-geomorphic units. Finally, the GUT Tier 3 geomorphic classification was used to segregate the sediment budget per GU for the whole scheme (Budget Segmentation Tool in GCD toolkit) and for both the 2014 and 2017 DEMs. Figure 1 demonstrates the series of outputs for a subreach of the scheme. 


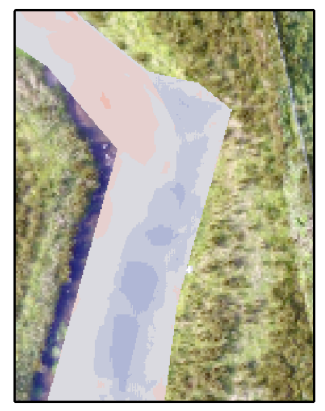

Elevation Change (2014-2017)

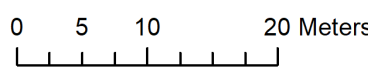

Elevation change (m)

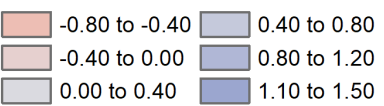

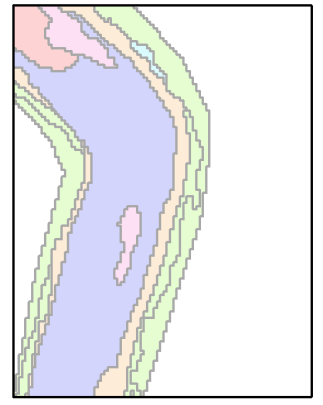

GUs 2014

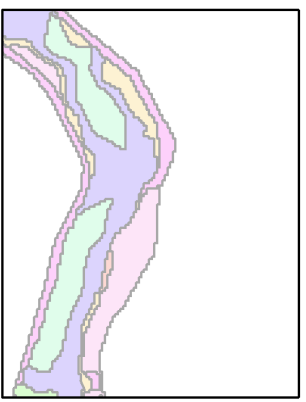

GUs 2017

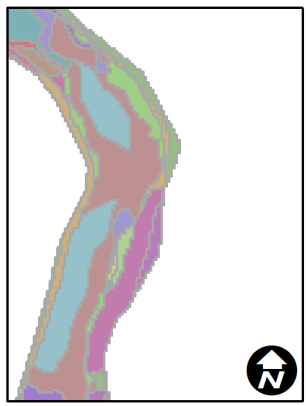

Change of GUs

Tier 3 GUT Classification

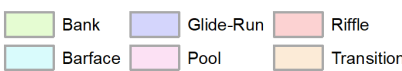

Change of GUs

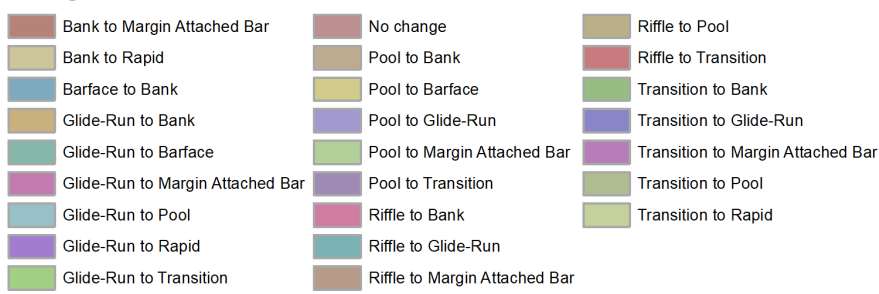

Figure 1. Processing Outputs for a sub reach of the Whit Beck Restoration Scheme. The GCD output (Elevation Change) maps erosion and deposition. The GUT outputs (Geomorphic Units, GU) map the type and extent of geomorphic units for the two surveys using the Wheaton et al. (2015) Tier 3 classification.

\section{RESULTS}

The sediment budget for 2014-2017 is provided here for context (Table 1). It is important to note that a historical extreme event (1/100 to $1 / 150$ years recurrence interval) was recorded for this area between these two surveys (the 2015 Cumbria floods, Burt et al, 2015, Russel et al., 2016).

Table 1. Sediment budget (2014-2017) for the $350 \mathrm{~m}$ long study reach. There is significant exchange of sediment between the two surveys. However, the net volume is positive indicating overall deposition. This net volume, once corrected for bed porosity, represents a minimum input volume of sediment to the reach during this time period.

\begin{tabular}{lll}
\hline & Volume $\left(\mathrm{m}^{3}\right)$ & Error \\
\hline Total volume of Erosion & $\begin{array}{l}2,172 \\
(35 \%)\end{array}$ & \pm 442 \\
Total volume of Deposition & $\begin{array}{l}4,135 \\
(65 \%)\end{array}$ & $\pm 1,226$ \\
Total Volume of Difference & 6,313 & $\pm 1,668$ \\
\hline Total Net Volume Difference. & 1,956 & $\pm 1,303$ \\
\hline
\end{tabular}

By mapping the GUs using the GUT workflow, it is possible to track transitions between GU types. Figure 2 shows how the geomorphic units identified from the 2014 survey developed during the $2014-2017$ period, expressed as a percentage of transitions per unit type. 

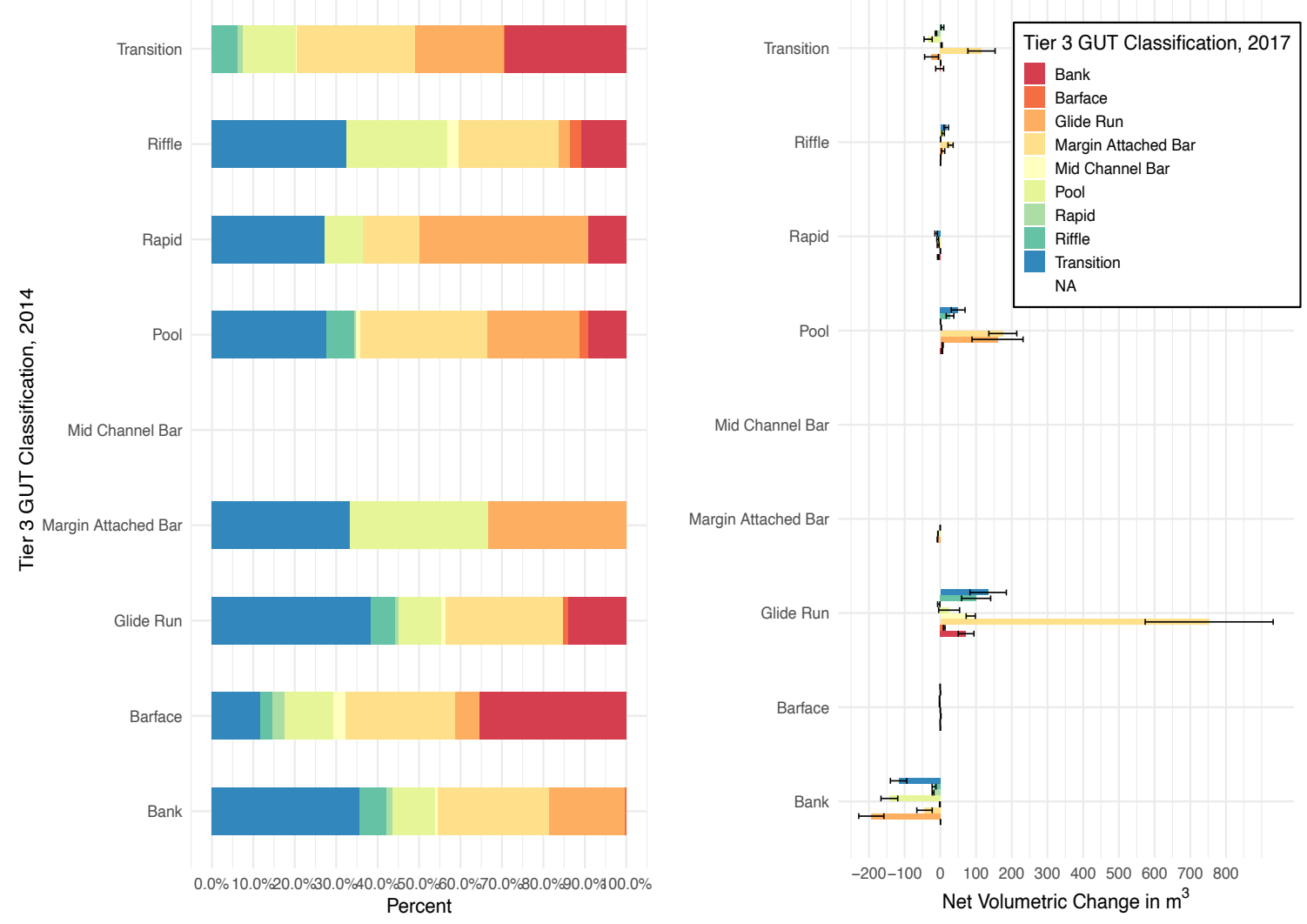

Figure 2. A. Transitions of GUs identified from the 2014 survey between 2014 and 2017, using Tier 3 GUT typology. B. Segmentation of the reach sediment budget per GU change (right).

\section{DISCUSSION}

The results indicate several associations that are directly relevant to the evaluation and the design of river restoration schemes. From the mapping of GU changes, it is possible to calculate that $83 \%$ of the GUs changed between the two surveys. Although it is necessary to expand this dataset, it is possible to observe morphological links between existing and developing GUs. For example, less than $5 \%$ of the changing areas indicate changes from dynamic GUs (e.g. rapids typically associated with erosional settings) to morphologically stable features (e.g. bars). It is also notable that all the parts of the bank that eroded contributed to the generation of new GUs (Figure 2B, Bank to Bank transition is negligible) highlighting the importance of allowing for lateral migration in restoration schemes. The latter is also highlighted by the budget segmentation results which show that a cumulative volume of $563 \mathrm{~m}^{3}$ of sediments from the banks was used to develop new GUs. This local erosion and the high sediment supply (as indicated by the whole budget, Table 1), were responsible for spatially limited (Fig 2A) but volumetrically significant (Fig 2B) depositional transitions. For example, $750 \mathrm{~m}^{3}$ of sediments were used to develop bars (Margin Attached Bars in Tier 3 Classification) in areas previously dominated by glides (Glide - Run in Tier 3 classification, Figure 3). By improving this type of observations, it will be possible to assign specific transition probabilities to GU transitions, which will enhance significantly both the process-based design and the evaluation of river restoration schemes. Finally, the segmentation of the budget per GU in Figure 2 shows the local net volumetric difference $\left(\mathrm{m}^{3}\right)$ of the surface associated with the mapped GU changes (Figures 1 and 2). 


\section{References}

Bangen SG, Kramer N, Wheaton JM, Bouwes N. 2017, The GUTs of the Geomorphic Unit Tool: What is under the hood. American Geophysical Union Fall Meeting, New Orleans, LA, pp. EP31D- 1901. https://doi.org/10.13140/RG.2.2.31118.66884.

Bangen SG, Wheaton JM, Bouwes N, Bouwes B, Jordan C. 2014. A methodological intercomparison 517 of topographic survey techniques for characterizing wadeable streams and rivers. 518 Geomorphology 206: 343-361. https://doi.org/10.1016/j.geomorph.2013.10.010.

Beechie TJ, Sear DA, Olden JD, Pess GR, Buffington JM, Moir H, Roni P, Pollock MM. 2010. Process- based Principles for Restoring River Ecosystems. BioScience 60: 209-222. https://doi.org/10.1525/bio.2010.60.3.7.

Belletti B, Rinaldi M, Bussettini M, Comiti F, Gurnell AM, Mao L, Nardi L, Vezza P. 2017. Characterising physical habitats and fluvial hydromorphology: A new system for the survey and classification of river geomorphic units. Geomorphology 283: 143-157. https://doi.org/10.1016/j.geomorph.2017.01.032.

Burt, S., McCarthy, M., Kendon, M. and Hannaford, J., 2016. Cumbrian floods, 5/6 December 2015. Weather, 71(2), pp.36-37.

Dietrich, J.T., 2017. Bathymetric structure-from-motion: extracting shallow stream bathymetry from multi-view stereo photogrammetry. Earth Surface Processes and Landforms, 42(2), pp.355364.

Downs PW, Kondolf GM. 2002. Post-Project Appraisals in Adaptive Management of River Channel Restoration. Environmental Management 29: 477-496. https://doi.org/10.1007/s00267-0010035-X.

Hawkins CP, Kershner JL, Bisson PA, Bryant MD, Decker LM, Gregory SV, McCullough DA, Overton CK, Reeves GH, Steedman RJ, Young MK. 1993. A Hierarchical Approach to Classifying Stream Habitat Features. Fisheries 18: 3-12. https://doi.org/10.1577/15488446(1993)018<0003:AHATCS>2.0.CO;2.

Lane SN, Chandler JH, Richards KS. 1994. Developments in monitoring and modelling smallscale 599 riverbed topography. Earth Surface Processes and Landforms 19: 349-368. 600 https://doi.org/10.1002/esp.3290190406.

McKean J, Nagel D, Tonina D, Bailey P, Wright CW, Bohn C, Nayegandhi A. 2009. Remote Sensing of 617 Channels and Riparian Zones with a Narrow-Beam Aquatic-Terrestrial LIDAR. Remote 618 Sensing 1: 1065

Passalacqua P, Belmont P, Staley DM, Simley JD, Arrowsmith JR, Bode CA, Crosby C, DeLong SB, Glenn NF, Kelly SA, Lague D, Sangireddy H, Schaffrath K, Tarboton DG, Wasklewicz T, Wheaton JM. 2015. Analyzing high resolution topography for advancing the understanding of mass and energy transfer through landscapes: A review. Earth-Science Reviews 148: 174- 193. https://doi.org/10.1016/j.earscirev.2015.05.012.

Russell, A., Perks, M., Large, A., Dunning, S. and Warburton, J., 2016, April. Fluvial geomorphological response along the upland sediment cascade during the record-breaking December 2015 floods, Cumbria, UK. In EGU General Assembly Conference Abstracts (Vol. 18). 
Vericat D, Wheaton JM, Brasington J. 2017. Revisiting the Morphological Approach: Opportunities 694 and Challenges with Repeat High-Resolution Topography. In: Tsutsumi D, Laronne J, editors. 695 Gravel-Bed Rivers: Process and Disasters, pp. 121-158. 696 https://doi.org/10.1002/9781118971437.ch5.

Wheaton JM, Brasington J, Darby SE, Sear DA. 2010. Accounting for uncertainty in DEMs from repeat topographic surveys: improved sediment budgets. Earth Surface Processes and Landforms 35: 136-156. https://doi.org/10.1002/esp.1886.

Wheaton JM, Fryirs KA, Brierley G, Bangen SG, Bouwes N, O'Brien G. 2015. Geomorphic mapping and taxonomy of fluvial landforms. Geomorphology 248: 273-295. https://doi.org/10.1016/j.geomorph.2015.07.010.

Williams, R., Byrne, P., Gilles, E., Hart, J., Hoey, T., Maniatis, G., Moir, H., Reid, H. and Ves, N., 2017, April. Quantifying the morphodynamics of river restoration schemes using Unmanned Aerial Vehicles (UAVs). In EGU General Assembly Conference Abstracts (Vol. 19, p. 17982). 